\title{
ANÁLISE DOS IMPACTOS DA SAÍDA DOS ESTADOS UNIDOS DA PARCERIA TRANSPACÍFICO (TPP): UMA ANÁLISE DO MERCADO DE CARNE DE FRANGO
}

\author{
Analysis of the Impacts of the Departure of the United States of the Trans-Pacific \\ Partnership (TPP): An Analysis of the Poultry Market
}

\begin{abstract}
RESUMO
Esse estudo objetiva analisar os impactos da saída dos Estados Unidos da Parceria Transpacífico (TPP) sobre o mercado de carne de frango. Destaca-se que mudanças na estrutura comercial de diferentes países já foram analisadas, sobretudo sobre setores de maneira agregada. Não sendo verificados estudos que evidenciam setores específicos, caso da carne de frango.A metodologia deriva de um Modelo de Equilíbrio Espacial na forma de um Problema de Complementaridade Mista (PCM), através de quatro cenários alternativos. O cenário 1 pressupõe a formação do TPP a partir da redução das barreiras tarifárias, já o cenário 2 estima a eliminação das barreiras tarifarias e não tarifárias. A partir da saída dos Estados Unidos do TPP, o cenário 3 simula a redução das barreiras tarifárias, e o cenário 4 pressupõe a eliminação das barreiras tarifárias e não tarifárias. Os resultados indicam que a saída dos Estados Unidos atenuam os impactos do TPP. Com base nos resultados, evidencia-se a importância de negociações de acordos comerciais aos países, para garantir expansão e acesso a novos mercados consumidores.
\end{abstract}

Angélica Pott de Medeiros

Universidade Federal de Santa Maria

apm_angelica@yahoo.com.br

Reisoli Bender Filho

Universidade Federal de Santa Maria

reisolibender@yahoo.com.br

Recebido em: 21/06/2017. Aprovado em: 02/03/2020.

Avaliado pelo sistema double blind review

Avaliador científico: Elisa Reis Guimarães

\begin{abstract}
This study aims to analyze the impact of the United States exit from the Transpacific Partnership on the poultry market. It is noteworthy that changes in the commercial structure of different countries have already been analyzed, especially on sectors in an aggregate manner. Not being checked studies that show specific sectors, the case of poultry. The methodology derives from a Spatial Equilibrium Model in the form of a Mixed Complementarity Problem, through four alternative scenarios. The first scenario assumes the formation of the TPP from the reduction of the tariff barriers, however the second scenario estimates the elimination of the tariff and non-tariff barriers. From the exit of the United States of the TPP, the third scenario simulates the reduction of tariff barriers, and forth scenario assumes the elimination of tariff and non-tariff barriers. The results indicate that the exit of the United States mitigates the impacts of the TPP. Based on the results, the importance of negotiating trade agreements with countries is highlighted, to guarantee expansion and access to new consumer markets.
\end{abstract}

Palavras-chave: Mercado Internacional de Carne de Frango. Acordos Comerciais. Equilíbrio Espacial.

Key-words: International Poultry Market. Commercial Agreements. Spatial Equilibrium.

\section{INTRODUÇÃO}

A fragmentação da produção com a instituição de cadeias globais de valor tem demandado por mudanças estruturais de governança do comércio internacional em diferentes países. Esse fato, combinado com um sistema multilateral de comércio que parece incapaz de atender a essas demandas, considerando-se o impasse na rodada Doha de negociações multilaterais da Organização Mundial do Comércio (OMC). Levou um conjunto de países partirem para a negociação de acordos regionais e plurilaterais, caso dos acordos que vem sendo chamados de "mega-acordos regionais", são eles: a Parceria Abrangente Econômica Regional (RCEP), liderada pela China; o Acordo de Parceria Transatlântica de Comércio e Investimento (TTIP), que envolve a União Europeia e os Estados Unidos; e a Parceria Transpacífico (TPP), liderada pelos Estados Unidos (CARNEIRO, 2014).

Pioneira, a Parceria Transpacífico, consiste em um acordo multilateral de livre comércio que vem sendo discutido desde 2005. Seus fundadores foram: Nova Zelândia, Chile, Cingapura e Brunei, os quais buscavam 
promover a integração econômica na Ásia-Pacífico, entre os seguintes países: Austrália, Brunei, Chile, Estados Unidos, Malásia, Nova Zelândia, Peru, Cingapura e Vietnã, além do Japão, México e Canadá.As negociações incluem acordos de investimentos estratégicos, estabelecimento de regras que abarcam barreiras comerciais, trabalho, meio ambiente e propriedade intelectual (AMARAL; MATTOS, 2013).

Com o objetivo de solidificar e estender seus interesses econômicos, políticos e militares no Pacífico, em meio a acordos bilaterais de livre comércio que já existiam, os Estados Unidos deram continuidade, em fevereiro de 2008, nas negociações da entrada no TPP (AMARAL; MATTOS, 2013). Contudo, a partir do momento em que os Estados Unidos decidiram participar das negociações, em setembro de 2008, tal acordo ganhou proporção global e foram necessárias decisões de outras economias da Ásia-Pacífico a respeito de se unirem ou não às negociações (ARMSTRONG, 2011, p. 4). Neste mesmo ano, outros três países, Austrália, Peru e Vietnã, se juntaram às negociações.

Neste processo de construção, somente em 4 de fevereiro de 2016, os ministros que representam a Austrália, Brunei, Canadá, Chile, Japão, Malásia, México, Nova Zelândia, Peru, Cingapura, Estados Unidos e Vietnã anunciaram a assinatura do TPP em Auckland, na Nova Zelândia. $\mathrm{O}$ acordo prometia definir um novo padrão de comércio e investimento à região, com o objetivo de aumentar a prosperidade de forma compartilhada, criar empregos, e promover o desenvolvimento econômico sustentável às nações (OFFICE OF THE UNITED STATES TRADE REPRESENTATIVE, 2016). Todavia, tal assinatura caracterizou um importante marco e também o início da próxima fase do TPP, voltado à conclusão dos processos internos, sendo que os países ainda podiam ratificá-lo.

Porém, em 2016, ocorreram as eleições nos Estados Unidos, as quais elegeram o republicano Donald Trump à presidência do país. Entre suas promessas de campanha, estava o interesse do candidato em retirar-se acordo, assim, em 23 de janeiro de 2017, o recém-empossado presidente assinou o decreto que retirou o país do acordo (CALDAS, 2017).

Diante do exposto, o presente estudo tem por objetivo verificar os impactos da retirada dos Estados Unidos do TPP, especificamente ao mercado de carne de frango mundial, pois dentre os produtos cárneos, os EUA apresenta maior volume em termos de exportações líquidas na carne de frango. Além disso, o país ocupa a primeira posição na produção mundial (USDA, 2016a). Nessa perspectiva, mudanças na estrutura comercial de diversos países já foram analisadas, porém, tais estudos concentram-se em análise dos diversos setores dos países, através da eliminação das barreiras tarifárias e não tarifárias (ASLAN et al., 2015; BURFISHER, 2014; PETRI; PLUMMER, 2016; THORSTENSEN; FERRAZ, 2014). Porém, verifica-se que a temática não possui discussão mais detalhada na literatura, pois, não foram encontrados estudos que evidenciam setores específicos, caso da carne de frango.

\section{PARCERIA TRANSPACIFÍCO (TPP)}

As origens da Parceria Transpacífico podem ser identificadas no acordo Trans-Pacific Strategic Economic Partnership (TPSEP), desenvolvido ainda em 2002, pela Nova Zelândia, Chile e Singapura, países membros da Asia Pacific EconomicCooperation (APEC). Firmado oficialmente em 2005, pelos membros originais, mais Brunei, o TPSEP, também conhecido como Pacific Four (P4) buscava inicialmente estabelecer relações econômicas entre os membros (ARMSTRONG, 2011, p. 4; CARNEIRO, 2015; FERGUSSON; MCMINIMY; WILLIAMS, 2015, p. 8).

A região da Ásia é formada por várias arquiteturas regionais, conforme a Figura 1, as quais competem nos aspectos econômicos e estratégicos. Exemplos disso estão na Ásia-central a ASEAN +3 (incluídos os membros da ASEAN - Brunei, Malásia, Singapura e Vietnã, mais China, Coréia do Sul e Japão) e a ASEAN +6 (membros da ASEAN e China, Coréia do Sul, Japão, Índia, Austrália e Nova Zelândia) também conhecida como Cúpula do Leste Asiático (East Asia Summit - EAS). No que abrange a Ásia-Pacífico, o mais abrangente é a Asia Pacific Economic Cooperation (APEC), que possui 21 membros, incluindo os Estados Unidos, e propôs em 2006, uma região de livre comércio da Ásia Pacífico, a Free Trade Areaof the Asia Pacific (FTAAP) (FERGUSSON; VAUGHN, 2011, p. 2).

Contudo, após a crise asiática de 1998/1999, só foram discutidos acordos de livre comércio na Ásia Ocidental em 2001, com a ASEAN +3 EconomicMinisters (AEM 3), que resultou em uma zona de livre comércio no leste da Ásia e o East Asia Free Trade Area (EAFTA), uma proposta conjunta da China e do Japão. Já em meados de 2006, o governo japonês fez uma proposta para uma parceria econômica mais abrangente envolvendo o leste da Ásia, ou Comprehensive Economic Partnership for 
East Asia (CEPEA), à cooperação comercial dos países do ASEAN +6. Assim, o TPP surgiu como solução para promover avanços que a FTAAP não havia conseguido até então (AMARAL; MATTOS, 2013).

Os países fundadores do TPP, inicialmente, buscavam formas de desenvolver os seus objetivos, tais como tornar mais ágeis os processos da APEC, em relação à liberação comercial e a abertura para novos investimentos, pactuando uma zona de livre comércio. A primeira rodada de negociações com os atuais membros ocorreu em março de 2011 e, em novembro do mesmo ano, em Melbourne - Austrália, os países anunciaram a realização das linhas gerais do acordo, cujo objetivo é melhorar o comércio e investimentos entre os parceiros, impulsionar a inovação, crescimento e desenvolvimento econômico e a criação e manutenção de postos de trabalho (OFFICE OF THE UNITED STATES TRADE REPRESENTATIVE, 2011).

Assim sendo, o TPP é uma expansão do acordo de 2005, dado pelo envolvimento dos Estados Unidos a partir de 2009, após a manifestação de interesse em 2008. Todavia, as negociações começaram efetivamente em 2010, quando foram incorporadas a Austrália, Vietnã e Peru, ainda, no final do mesmo ano, a Malásia ingressou. Já em 2012, Canadá e México também aderiram. Ainda, com interesse, mas mantendo a condição de observadores, estavam a Coreia do Sul, Filipinas, Taiwan e Japão. Esse último oficializou seu ingresso em 2013 (NUNES LINS, 2014; MERCURIO, 2014, p. 1).

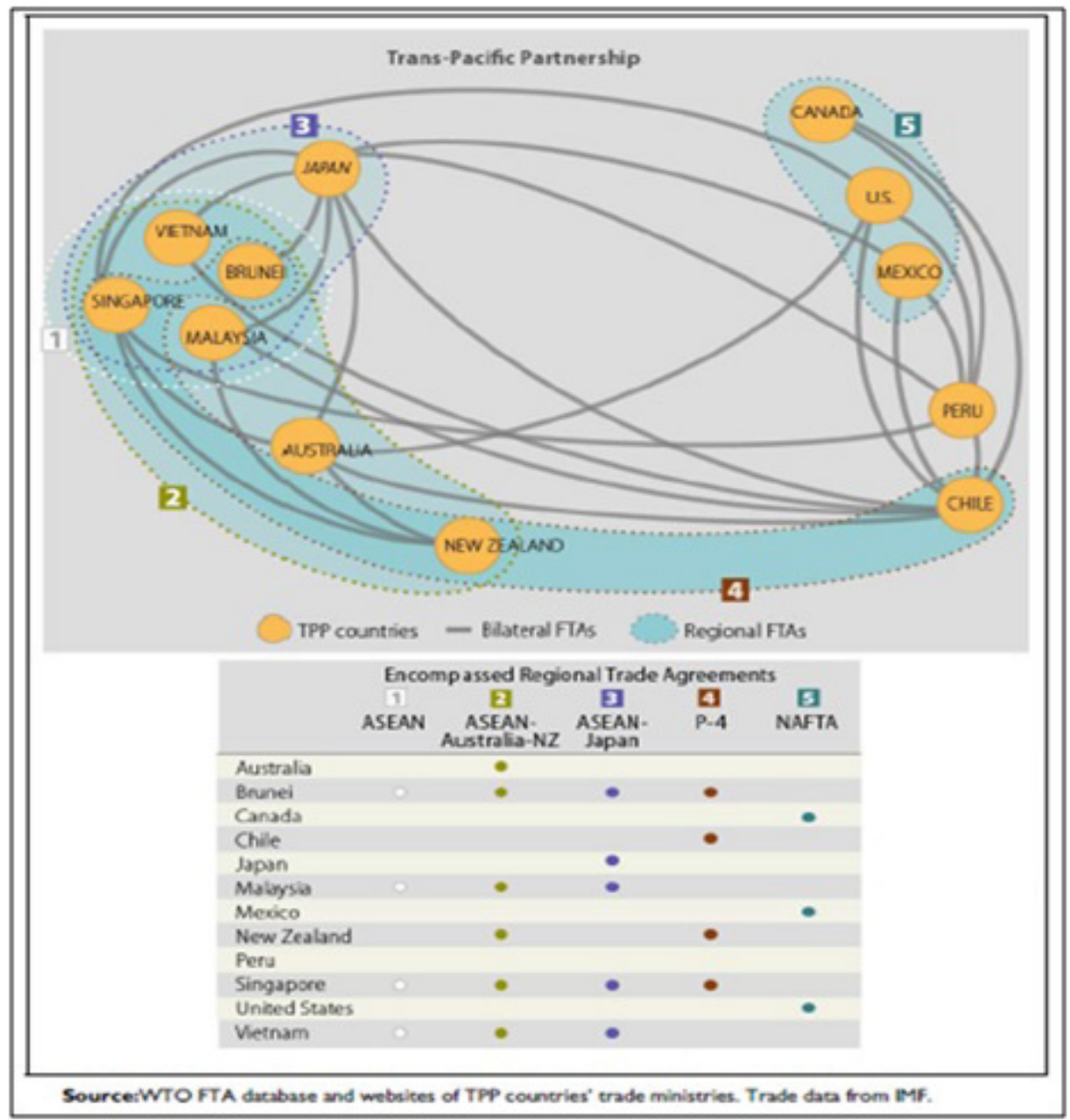

FIGURA 1 - Acordos existentes entre os membros do TPP Fonte: Fergusson, McMinimy e Williams (2015, p. 9)

Organizações Rurais \& Agroindustriais, Lavras, v. 20, n. 3/4, p. 170-186, 2018 
Em termos econômicos, o TPP liga um grupo que representa cerca de $40 \%$ do PIB e cerca de um terço do comércio mundial. Os esforços concentram-se em tornar o TPP um acordo comercial de alto padrão. Diante disso, os Estados Unidos e o Japão, buscam alcançar um acordo a respeito do acesso ao mercado de várias commodities agrícolas nas quais o Japão considera como sensíveis e de proteção de importação contínua (FERGUSSON; MCMINIMY; WILLIAMS, 2015, p. 26).

Em relação às normas do TPP, os membros discutem sobre como lidar com a saúde humana e animal, nas quais se incluem questões sanitárias e normas fitossanitárias, associadas ao comércio de produtos agrícolas, que vai além daquelas encontrados na Organização Mundial do Comércio (OMC). Quanto às Barreiras Técnicas ao Comércio, as quais buscam proteger a saúde e segurança dos consumidores, a fim de minimizar as distorções, os membros devem aderir ao Acordo sobre Barreiras Técnicas ao Comércio (Agreementon Technical Barriersto Trade) da OMC, que estabelece regras e procedimentos a serem seguidos pelos membros, como também exige a transparência no que tange aos regulamentos aplicados (FERGUSSON; MCMINIMY; WILLIAMS, 2015, p. 30).

$\mathrm{Na}$ contramão deste processo, Amaral e Mattos (2013) enfatizam que nenhum dos países do BRICS (Brasil, Rússia, Índia, China e África do Sul), apesar de alguns deles pertencerem ao APEC, caso da China e da Rússia, integra o TPP. Fato que se deve às frequentes manifestações dos Estados Unidos referentes à possível não aplicabilidade dos Direitos de Propriedade Intelectual (DPI) pela China, a qual afeta as empresas norteamericanas naquele país. Com isso, fortalecendo a hipótese de que o maior objetivo estratégico da TPP seria isolar a China na região Ásia Pacífico.

Formalmente, o acordo consiste em cerca de vinte capítulos, onde seus membros idealizam como o maior e de mais alto padrão, buscando eliminar tarifas e barreiras não tarifárias ao comércio de bens, serviços e agricultura, além de tratar de questões como o direto de propriedade intelectual e o investimento estrangeiro direto. Conforme
Fergusson, Mcminimy e Williams (2015, p. 6), este seria o "acordo do século", abordando assuntos novos e transversais, apresentados por uma economia cada vez mais globalizada.

Apesar das negociações terem sido concluídas em outubro de 2015, com expectativas de que as empresas direcionassem as suas atividades para dentro do bloco, aumentando a regionalização das cadeias de valor, somente em 4 de fevereiro de 2016, os ministros que representam a Austrália, Brunei, Canadá, Chile, Japão, Malásia, México, Nova Zelândia, Peru, Cingapura, Estados Unidos e Vietnã anunciaram a assinatura do Acordo Transpacífico em Auckland, na Nova Zelândia. Todavia, tal assinatura caracterizou um importante marco e também o início da próxima fase do TPP, voltado à conclusão dos processos internos.

Conforme Nakagawa (2017) o acordo possuía uma cláusula de que o mesmo só entraria em vigor diante do consentimento de no mínimo 6 países, além de $85 \%$ do PIB no seu conjunto. Diante da saída dos Estados Unidos, o TPP não pôde entrar em vigor. Diante disso, questionou-se sobre a efetivação do acordo, haja vista que os EUA vinham liderando o movimento em prol do TPP, além dos outros membros negociarem o acordo em virtude do acesso a economia norte-americana. Apesar disso, os onze países restantes deram continuidade as negociações do acordo, constituindo o CPTPP (The Comprehensive and Progressive Agreement for TransPacific Partnership), assinado em março de 2018 (MIYAZAKI, 2019).

\subsection{Estudos e Evidências sobre o Acordo Transpacífico}

Dada à importância e os impactos que extrapolam os países envolvidos no acordo comercial, diversos estudos já realizados buscaram quantificar os efeitos deste nas economias, tanto dos membros quando dos não membros. O detalhamento das principais propostas desenvolvidas em termos analíticos, metodológicos como também os resultados se encontram expostos no Quadro 1. 


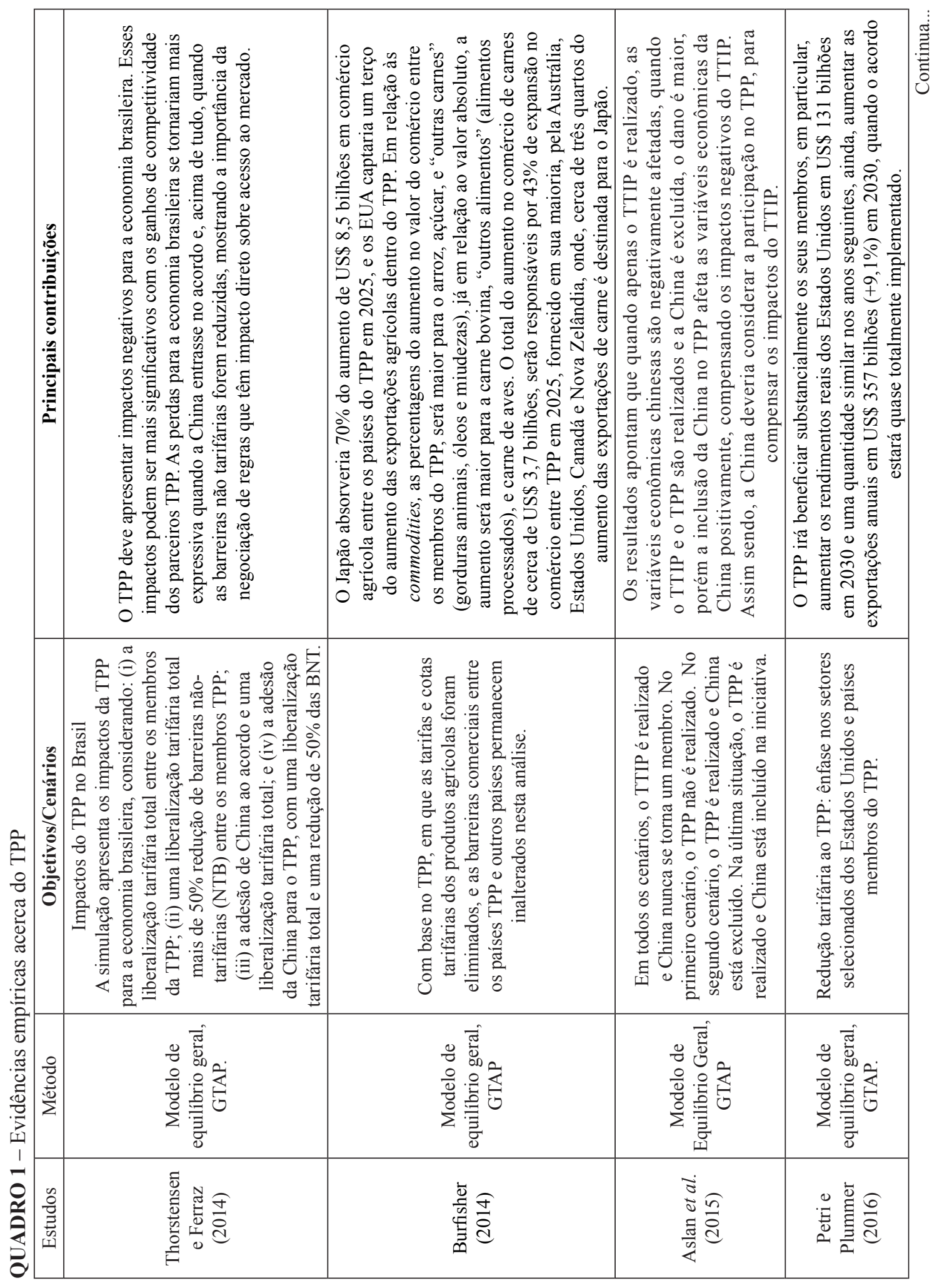

Organizações Rurais \& Agroindustriais, Lavras, v. 20, n. 3/4, p. 170-186, 2018 


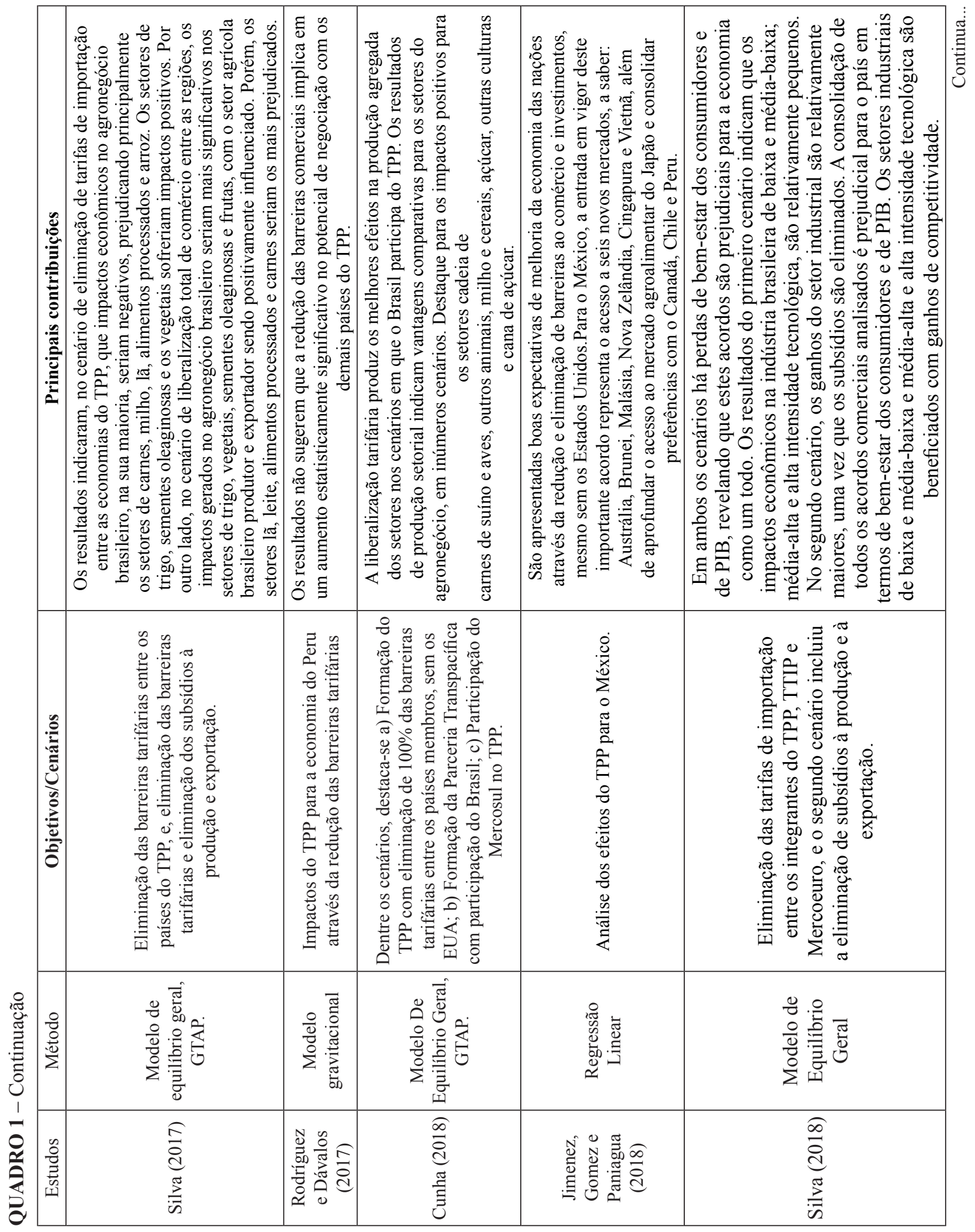

Organizações Rurais \& Agroindustriais, Lavras, v. 20, n. 3/4, p. 170-186, 2018 


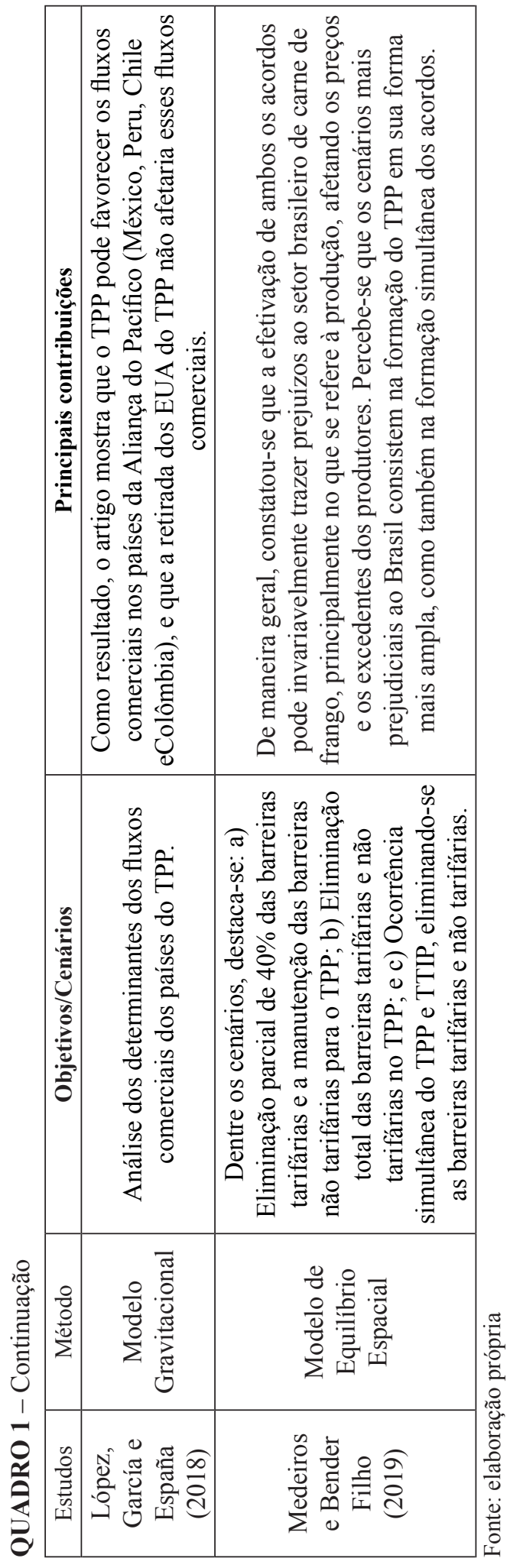

Verifica-se que os estudos selecionados sobre o Acordo Transpacífico utilizam em grande parte o Modelo de Equilíbrio Geral, diante disso, as análises concentram-se em setores de forma agregada, como o setor industrial ou o agronegócio. Ademais, verifica-se também que são usados outros modelos econométricos para a análise, sobretudo para verificar a influência das barreiras tarifárias sobre os fluxos comerciais dos países.

\section{METODOLOGIA}

\subsection{O Modelo de Equilíbrio Espacial e o Problema de Complementaridade Mista}

A metodologia utilizada consiste em um Problema de Complementaridade Mista (PCM), derivado do modelo de equilíbrio espacial proposto por Samuelson (1952), que formaliza a Função de Ganho Social Líquido (Net Social Payoff -NSP), no qual os excedentes do produtor e do consumidor são somados, resultando a um ponto ótimo global.

Todavia, Takayama e Judge (1964) estenderam a formulação de Samuelson (1952), expressando o modelo de maximização por meio de uma função objetivo e suas restrições, considerando-se um produto consumido em “j” regiões e produzido em "i", admitindo a existência de equilíbrio de mercado, de acordo com as funções de oferta e demanda. A função objetivo é compreendida por:

$$
N S P=\sum_{j=1}^{J} \int_{0}^{q_{j}^{d}} p_{j}^{d} d q_{j}^{d}-\sum_{i=1}^{I} \int_{0}^{q_{i}^{s}} p_{i}^{s} d q_{i}^{s}-\sum_{i=1}^{I} \sum_{j=1}^{J} t_{i, j} X_{i, j}
$$

Sujeito a:

$$
\begin{aligned}
& \sum_{j=1}^{J} X_{i, j}-q_{i}^{s} \leq 0 ; \\
& q_{j}^{d}-\sum_{i=1}^{I} X_{i, j} \leq 0 ;
\end{aligned}
$$

$q_{i}^{s} \geq 0, q_{j}^{d} \geq 0$ e $X_{i, j} \geq 0$

em que $p_{j}^{d}$ é a função de demanda na j-ésima região; $p_{i}^{s}$ é a função de oferta na i-ésima região; $q_{j}^{d}$ é a quantidade consumida na j-ésima região; $q_{i}^{s}$ é a quantidade produzida na i-ésima região;

Organizações Rurais \& Agroindustriais, Lavras, v. 20, n. 3/4, p. 170-186, 2018 
$\mathrm{X}_{\mathrm{i}, \mathrm{j}}$ é a quantidade de produto comercializada entre as regiões $i$ e $j ; \mathrm{t}_{\mathrm{i}, \mathrm{j}}$ é o custo unitário de transporte entre as regiões $i$ e $j$.

As Equações de 2 a 4 definem as restrições da NSP. A restrição definida em (2) estabelece que nenhuma região pode consumir e exportar mais que a quantidade produzida, enquanto que a seguinte (3), estabelece que nenhuma região pode consumir mais que a soma de sua produção e das suas importações totais. E, a última restrição (4), garante que as quantidades produzidas, consumidas e comercializadas não tenham valores negativos (BENDER FILHO, 2006).

A Equação 1 determina a função Lagrangeana, a qual é redefinida na Equação em (5). Essa função está associada às condições de Kuhn-Tucker e permitirá obter uma solução corresponde a um ótimo global, desde que as condições de Kuhn-Tucker sejam atendidas.

$$
\begin{aligned}
& L=\sum_{j=1}^{J} \int_{0}^{q_{j}^{d}} p_{j}^{d} d q_{j}^{d}-\sum_{i=1}^{I} \int_{0}^{q_{i}^{s}} p_{i}^{s} d q_{i}^{s}-\sum_{i=1}^{I} \sum_{j=1}^{J} t_{i, j} X_{i, j} \\
& -\sum_{i=0}^{I} \varphi_{i}\left[\sum_{j=1}^{J} X_{i, j}-q_{i}^{s}\right]-\sum_{j=1}^{J} \lambda_{j}\left[q_{j}^{d}-\sum_{i=1}^{I} X_{i, j}\right]
\end{aligned}
$$

De acordo com Nagurneyet al. (1996), ao incorporarem-se instrumentos de políticas comerciais, como quotas, tarifas e barreiras não tarifárias, aos modelos de equilíbrio espacial, possibilita-se a obtenção de resultados mais realísticos e mais precisos da realidade. Porém, requer algumas modificações nas condições do modelo convencional de equilíbrio espacial, onde os mercados devem conjecturar a condição de concorrência perfeita e produtos homogêneos. Assim, a demanda, a oferta e a quantidade transportada de todas as regiões importadoras e exportadoras devem atender as seguintes restrições:

$t_{i, j}+\varphi_{i}=\lambda_{j}$, se $X_{i, j}>0$

$t_{i, j}+\varphi_{i} \geq \lambda_{j}$, se $X_{i, j}=0$

A partir do NSP, o PCM possui como vantagem a possibilidade de inserção de tarifas ao modelo. Assim sendo, esse modelo permite a simulação de alterações de instrumentos de política comercial, como as barreiras tarifárias e as quotas (ALVIM; WAQUIL, 2007). Assim, as equações podem ter igualdades e desigualdades, sendo que o objetivo da centralização desse problema parte das funções de demanda e oferta, e das condições de KuhnTucker (GRUNDLING; WAQUIL, 2015). A seguir são apresentadas as condições de um PCM, contendo os instrumentos de política comercial.

$$
\begin{aligned}
& \left(\sum_{j}^{J} X_{i, j}-q_{i}^{s}\right) \cdot \varphi_{i}=0, \forall_{i, j}, \varphi_{i} \geq 0 \\
& \left(q_{j}^{d}-\sum_{i}^{I} X_{i, j}\right) \cdot \lambda_{j}=0, \forall_{i, j}, \quad \lambda_{j} \geq 0
\end{aligned}
$$

$\left(\lambda_{j}-\left(\varphi_{i}+t_{i, j}\right) \cdot\left(1+\operatorname{tar}_{i, j}+q r_{i, j}\right)\right) \cdot X_{i, j}=0, \forall_{i, j}, X_{i, j} \geq 0$

$\left(Q_{i, j}-X_{i, j}\right) \cdot q r_{i, j}=0, \forall_{i, j}, q r_{i, j} \geq 0$

sendo $i, j$ são as regiões; $q_{j}^{d}$ é a quantidade consumida na região $j ; q_{i}^{s}$ é a quantidade produzida na região $i ; X_{i, j}$ é a quantidade de produto comercializada entre as regiões $i$ e $j ; t_{i, j}$ é o custo de transporte entre as regiões $i$ e $j ; t_{a r}$ é a tarifa imposta sobre o produto da região $i$ na região $j$; $q r_{i, j}$ é a tarifa aplicada quando o fluxo exceder a quota tarifária $\left(Q_{i, j}\right) ; \lambda_{j}$ multiplicador de Lagrange: preço-sombra na região produtora $j \mathrm{e} ; \varphi_{i}$ multiplicador de Lagrange: preço-sombra na região consumidora $i$.

As equações permitem estimar os preços-sombra, que definem o preço máximo que o consumidor está disposto a pagar pela unidade adicional do produto, o preço mínimo que o produtor está disposto a receber para produzir uma unidade adicional do produto, assim como as quantidades produzidas e consumidas, e os fluxos comerciais. De acordo com Bender Filho e Alvim (2007), as equações em (10) e (11) determinam os fluxos comerciais entre as regiões definidas por meio da incorporação ao modelo de equilíbrio espacial os instrumentos de política comercial, como as tarifas, subsídios, quotas tarifarias e barreiras não tarifárias, além de ser considerado o custo de transporte entre as regiões.

A partir dessa metodologia, busca-se estimar os ganhos ou perdas para o mercado americano de carne de frango a partir da participação ou não do Acordo Transpacífico (TPP), por meio da simulação das alterações tarifárias e não tarifárias aos membros do acordo. Para atingir o objetivo do estudo foram propostos quatro cenários (Ver Quadro 2), onde as 
barreiras de comércio são alteradas de acordo com a proposta do TPP, com a finalidade de verificar os impactos da participação e da posterior saída dos Estados Unidos do TPP, na produção e nos fluxos comerciais do mercado de carne de frango.

QUADRO 2 - Cenários propostos

\begin{tabular}{|c|c|c|c|}
\hline Acordo & Cenários & Tarifas & BNT* \\
\hline $\begin{array}{c}\text { Acordo } \\
\text { Transpacífico }\end{array}$ & 1 & Redução de 40\% & Manutenção \\
\cline { 2 - 4 } & 2 & Eliminação & Eliminação \\
\hline $\begin{array}{c}\text { Acordo } \\
\text { Transpacífico } \\
\text { (sem os EUA) }\end{array}$ & 3 & Redução de 40\% & Manutenção \\
\cline { 2 - 4 } & 4 & Eliminação & Eliminação \\
\hline
\end{tabular}

Fonte: elaborado pelos autores

* Barreiras não tarifárias - BNT

Os cenários propostos foram desenvolvidos levando em consideração as condições das negociações do TPP. O primeiro cenário simula a eliminação parcial das barreiras tarifárias (40\%) e a manutenção das barreiras não tarifarias aos membros do TPP, de acordo com Office of the United States Trade Representative- USTR (2014), agência responsável pela política comercial dos Estados Unidos, que prevê uma redução de $40 \%$ nos impostos de exportação na carne de frango dos Estados Unidos, decorrentes da efetivação do TPP. O cenário 2 pressupõe a eliminação total das barreiras tarifárias e não tarifárias, conforme consta no calendário de eliminação tarifária do TPP (USTR, 2015).

Os cenários 3 e 4 consideram o TPP após a saída dos Estados Unidos do acordo. Sendo assim, o cenário 3 simula a eliminação parcial de $40 \%$ das barreiras tarifárias, ao passo que o cenário 4 pressupõe a eliminação total das barreiras tarifárias e não tarifárias ao TPP.

As informações necessárias à implementação do modelo de equilíbrio espacial, na forma de um Problema de Complementaridade Mista encontram-se detalhados na Tabela 1. Ressalta-se que as informações de produção, exportação e importação para os países e regiões consideradas no trabalho estruturam os fluxos comerciais do triênio 2011-2013, sendo utilizada a média desse período para construção do cenário base. Operacionalmente, foi utilizado o solver MILES, pertencente ao GAMS (General Algebraic Modelling System), criado em 1994.
Além dos dados referentes ao fluxo comercial, elasticidades, barreiras tarifárias, barreiras não tarifárias e subsídios, foram necessários os custos de transporte da carne de frango entre as regiões analisadas, sendo esses calculados levando em consideração os custos portuários do Porto de Rio Grande (2016) e o simulador de preço de exportação do MDIC (2016). Assim, foi possível obter o custo em US\$ da tonelada por milha marítima, para posterior cálculo do custo levando em consideração as distâncias das regiões/países, coletados junto ao Banco Mundial (2005).

TABELA 1 - Dados necessários à implementação do modelo

\begin{tabular}{|c|c|c|}
\hline Dados & Descrição & Fonte \\
\hline Fluxos comerciais & $\begin{array}{l}\text { Produção, importação } \\
\text { e exportação carne de } \\
\text { frango - } 2011 \text { a } 2013 .\end{array}$ & $\begin{array}{c}\text { FAO } \\
(2016)\end{array}$ \\
\hline $\begin{array}{c}\text { Elasticidades-preço } \\
\text { de demanda e de } \\
\text { oferta }\end{array}$ & Elasticidades de carnes. & $\begin{array}{r}\text { USDA } \\
(2016 b)\end{array}$ \\
\hline Barreiras tarifárias & $\begin{array}{c}\text { Tarifas (ad valorem) ao } \\
\text { comércio de carne de } \\
\text { frango. }\end{array}$ & $\begin{array}{l}\text { OMC } \\
(2016)\end{array}$ \\
\hline $\begin{array}{l}\text { Barreiras não } \\
\text { tarifárias }\end{array}$ & $\begin{array}{l}\text { Medidas sanitárias, } \\
\text { fitossanitárias e técnicas. }\end{array}$ & $\begin{array}{l}\text { OMC } \\
(2016)\end{array}$ \\
\hline Subsídios & $\begin{array}{l}\text { Repasses aos produtores } \\
\text { de frango - } 2002 \text { a } 2004 .\end{array}$ & $\begin{array}{l}\text { OECD } \\
(2005)\end{array}$ \\
\hline
\end{tabular}

Fonte: Elaborado pelos autores

$\mathrm{O}$ estudo engloba o mercado mundial da carne de frango. A fim de auxiliar modelagem e a análise dos cenários, foram agrupados alguns países, porém, buscouse manter os países do TPP desagregados. Para que fosse possível acompanhar as alterações comerciais em cada país. Assim, o modelo consiste em vinte e uma regiões (Ver Quadro 3).

Destaca-se que os países do TPP nas simulações são compostos pelas seguintes regiões:Japão, Malásia, Austrália, Peru, Estados Unidos, demais membros do TPP (Vietnã, Cingapura, Brunei, Nova Zelândia e Chile), e restante do NAFTA (Canadá e México),porém, Estados Unidos não é considerado membro do acordo na simulação dos cenários 3 e 4 . 
QUADRO 3 - Distribuição das regiões na construção dos cenários alternativos

\begin{tabular}{|c|c|}
\hline Abreviação & Países/Regiões \\
\hline bra & Brasil \\
\hline arg & Argentina \\
\hline mcs & $\begin{array}{c}\text { Restante do MERCOSUL (Paraguai, Uruguai e } \\
\text { Venezuela) }\end{array}$ \\
\hline per & Peru \\
\hline das & Demais da América do Sul \\
\hline usa & Estados Unidos \\
\hline naf & Aestante do NAFTA (Canadá e México) \\
\hline aus & Demaísia do ASEAN ${ }^{1}$ \\
\hline mas & África \\
\hline ase & Demais do Oriente Médio \\
\hline afr & Arábia Saudita \\
\hline ome & Japão \\
\hline sau & Demais da Ásia \\
\hline jpn & China \\
\hline Vietnã, Laos, Mianmar e Camboja. Fonte: Elaborado pelos \\
autores
\end{tabular}

\section{RESULTADOS E DISCUSSÃO DOS CENÁRIOS PROPOSTOS}

\subsection{Cenário base e Calibragem do Modelo}

A validação das simulações é realizada a partir do processo de calibragem do modelo, que consiste na comparação entre os valores estimados com os valores observados (reais), estruturando assim o cenário base. De maneira geral, verificou-se que as diferenças se mantiveram menores que $8 \%$ (Ver Tabela 2 ), indicando a validade do cenário base, tendo em vista que as estimações condizem com os valores observados. Além disso, no cenário base o modelo apresentou harmonia em relação aos fluxos comerciais da carne de frango estimados e os reais. Conforme as estimações, os principais produtores da carne de frango são os Estados Unidos, Brasil, China e União Europeia. E os maiores consumidores, os Estados Unidos, China, União Europeia, Brasil e países do Oriente Médio.

Levando em consideração os principais exportadores da commodity, observa-se que o Brasil concentra as suas exportações ao Oriente Médio, em destaque a Arábia Saudita, assim como para o Japão, e alguns países do TPP. Já os Estados Unidos, exportam para os países do NAFTA, África e alguns países da Ásia.

De maneira geral, o cenário base estimado, atendeu os requisitos de validação, pois os resultados simulados foram condizentes com o cenário observado. A partir disso, são analisados os resultados da simulação dos cenários alternativos, quanto ao comportamento da produção, preços, consumo, excedentes de produtor e consumidor, além dos fluxos comerciais.

\subsection{Análise dos Impactos da Implementação dos Cenários Alternativos sobre Mercado Mundial de Carne de Frango}

\subsubsection{Análise das Variações dos Níveis de Produção}

Levando-se em consideração o primeiro cenário, que supõe a participação dos 12 membros do TPP (representados nesse estudo pelas seguintes regiões: per, usa, naf, aus, mas, jpn e tpp), supondo a redução de 40\% das barreiras tarifárias e a manutenção das barreiras não tarifárias entre os membros, é possível verificar, pequenas perdas em termos de produção aos países do MERCOSUL, de $0,1 \%$, representando cerca de 11.600 toneladas (Ver Tabela 3). Situação semelhante ocorre com o Oriente Médio e a Arábia Saudita, representando uma redução de 4.500 toneladas. E ainda, aos demais países do TPP, tendo reduzido de seu volume de produção cerca de 900 toneladas.

Por outro lado, as regiões que apresentaram crescimento foram a Austrália e os demais países do Asean, $0,7 \%$ e $0,2 \%$, respectivamente. Tal acréscimo representa cerca de 7.000 toneladas a Austrália, e aproximadamente 8.000 toneladas aos demais países do Asean. Essas alterações se devem a redução das barreiras tarifárias entre os membros do TPP, aquecendo a produção da Austrália, em detrimento da produção dos países do MERCOSUL. Tendo em vista que, a Austrália passa a exportar ao Japão, devida a redução tarifária, produto que anteriormente era destinado aos demais países do Asean, que aumenta 
a produção para manter a demanda interna. Ademais, essa demanda do Japão era atendida pelo Brasil, porém apresenta-se um desvio de comércio, devido à facilitação do comércio com o TPP.

A partir da simulação do segundo cenário, que pressupõe a eliminação total das barreiras, é possível verificar mudanças mais expressivas, como por exemplo, o Brasil, que apresenta uma redução de 7,6\%, o que representa uma redução de 870.000 toneladas. Assim como para o restante do MERCOSUL, que apresenta uma redução de aproximadamente 134.000 toneladas. Reduções também são verificadas nos demais países do Asean (5\%), demais países do Oriente Médio $(5,4 \%)$ e Arábia Saudita
(5,4\%), e no Reino Unido (3,1\%), que conjuntamente representa uma redução de aproximadamente 700.000 toneladas produzidas. Ainda, verifica-se uma redução de produção da Austrália (2,2\%), Malásia (12,6\%), Japão $(7,6 \%)$, e demais países do TPP $(7,6 \%)$, os quais são países membros do TPP. Essas reduções representam, cerca de 400.000 toneladas.

Por outro lado, algumas regiões apresentam expansão em termos de produção, como é o caso dos demais países da América do Sul $(0,6 \%)$, países da África (19,2\%), demais países da Ásia (15,1\%). O mesmo verificou-se no Peru (16,1\%), Estados Unidos $(2,7 \%)$, demais países do NAFTA $(11,3 \%)$, representando um

TABELA 2 - Valores observados, estimados e variações da produção, consumo e preços da carne de frango (média 2011-2013)

\begin{tabular}{cccccccccc}
\hline & \multicolumn{3}{c}{ Valores Observados } & \multicolumn{3}{c}{ Valores Estimados } & \multicolumn{3}{c}{ Variações } \\
\cline { 2 - 9 } Países & Prod. & Consumo & Preços & Prod. & Consumo & Preços & Prod. & Consumo & Preços \\
\cline { 2 - 10 } & 1.000 t. & 1.000 t. & US\$ & 1.000 t. & 1.000 t. & US\$ & $\%$ & $\%$ & $\%$ \\
\hline Brasil & $11.781,34$ & $8.222,98$ & 1,8 & $11.481,97$ & $8.715,41$ & 1,73 & $-2,54$ & 5,99 & $-3,83$ \\
Argentina & $1.835,87$ & $1.519,96$ & 1,8 & $1.826,76$ & $1.448,07$ & 1,78 & $-0,5$ & $-4,73$ & $-0,89$ \\
Demais países do MERCOSUL & 111,17 & 96,89 & 1,68 & 115,37 & 95,94 & 1,76 & 3,78 & $-0,97$ & 5 \\
Peru & $1.152,97$ & $1.172,96$ & 1,24 & $1.163,94$ & $1.163,94$ & 1,26 & 0,95 & $-0,77$ & 1,37 \\
Demais países da América do Sul & $3.123,51$ & $3.357,67$ & 1,32 & $3.250,67$ & $3.250,67$ & 1,4 & 4,07 & $-3,19$ & 5,98 \\
Estados Unidos & $17.181,07$ & $13.699,19$ & 1,26 & $17.092,92$ & $14.485,07$ & 1,2 & $-0,51$ & 5,74 & $-4,6$ \\
Resto do Nafta & $3.924,65$ & $4.562,84$ & 1,4 & $3.855,06$ & $4.573,82$ & 1,35 & $-1,77$ & 0,24 & $-3,5$ \\
Austrália & $1.051,04$ & $1.024,32$ & 1,95 & $1.059,08$ & $1.041,90$ & 2 & 0,77 & 1,72 & 2,41 \\
Malásia & $1.247,92$ & $1.283,25$ & 2,19 & $1.267,42$ & $1.267,42$ & 2,24 & 1,56 & $-1,23$ & 2,42 \\
Demais Países da Asean & $5.257,90$ & $5.281,84$ & 2,08 & $5.314,09$ & $5.331,27$ & 2,11 & 1,07 & 0,94 & 1,35 \\
África & $3.264,64$ & $4.488,74$ & 1,69 & $3.148,45$ & $4.654,38$ & 1,62 & $-3,56$ & 3,69 & $-4,38$ \\
Oriente Médio & $6.424,11$ & $7.544,95$ & 1,98 & $6.643,30$ & $7.385,41$ & 2,11 & 3,41 & $-2,11$ & 6,41 \\
Arábia Saudita & 571,56 & $1.327,43$ & 2,12 & 565,61 & $1.423,22$ & 2,08 & $-1,04$ & 7,22 & $-1,93$ \\
Japão & $1.424,21$ & $1.854,67$ & 2,47 & $1.413,09$ & $1.998,89$ & 2,41 & $-0,78$ & 7,78 & $-2,51$ \\
Demais países da Asia & 983,51 & $1.452,62$ & 1,4 & $1.010,49$ & $1.393,64$ & 1,46 & 2,74 & $-4,06$ & 4,14 \\
China & $12.456,72$ & $12.766,78$ & 2,03 & $12.686,62$ & $12.686,62$ & 2,07 & 1,85 & $-0,63$ & 2,07 \\
Rússia & $3.219,21$ & $3.668,50$ & 1,55 & $3.391,93$ & $3.391,93$ & 1,68 & 5,37 & $-7,54$ & 8,26 \\
Reino Unido & $1.464,80$ & $1.586,95$ & 2,97 & $1.440,41$ & $1.685,25$ & 2,83 & $-1,67$ & 6,19 & $-4,68$ \\
UE (27) & $9.516,02$ & $8.321,80$ & 2,66 & $8.968,16$ & $8.968,16$ & 2,47 & $-5,76$ & 7,77 & $-7,14$ \\
Resto do TPP & $1.434,45$ & $1.999,73$ & 2,32 & $1.375,90$ & $2.110,21$ & 2,16 & $-4,08$ & 5,53 & $-6,94$ \\
Resto do mundo & $6.674,38$ & $7.215,48$ & 2,26 & $7.003,06$ & $7.003,06$ & 2,41 & 4,92 & $-2,94$ & 6,73 \\
\hline
\end{tabular}

Fonte: FAO (2016), resultados da pesquisa

Organizações Rurais \& Agroindustriais, Lavras, v. 20, n. 3/4, p. 170-186, 2018 
acréscimo de aproximadamente 1.100.000 toneladas, à esses membros do TPP. Observa-se que há uma centralização da produção em alguns países do TPP, compensado as reduções das demais regiões. Ainda, verificou-se redução de produção em países membro do acordo, que possivelmente foi causada pelo desvio de comercio a uma região com melhores condições e um preço mais competitivo, caso dos Estados Unidos e dos demais países do NAFTA.

TABELA 3 - Variações da produção nos cenários alternativos em relação ao cenário base (\%)

\begin{tabular}{ccccc}
\hline Região & Cenário 1 & Cenário 2 & Cenário 3 & Cenário 4 \\
\hline bra & $-0,1$ & $-7,6$ & $-0,1$ & $-5,0$ \\
arg & $-0,1$ & $-6,7$ & $-0,1$ & $-6,9$ \\
mcs & $-0,1$ & $-9,4$ & $-0,1$ & $-8,4$ \\
per & 0,0 & 16,1 & 0,0 & 12,7 \\
das & 0,0 & 0,6 & 0,0 & 0,0 \\
usa & 0,0 & 2,7 & 0,0 & 2,2 \\
naf & 0,0 & 11,3 & 0,0 & 9,2 \\
aus & 0,7 & $-2,2$ & 0,7 & $-3,2$ \\
mas & 0,0 & $-12,6$ & 0,0 & $-1,6$ \\
ase & 0,2 & $-5,0$ & 0,2 & $-7,3$ \\
afr & 0,0 & 19,2 & 0,0 & 15,3 \\
ome & $-0,1$ & $-5,4$ & $-0,1$ & $-3,6$ \\
sau & $-0,1$ & $-5,4$ & $-0,1$ & $-3,6$ \\
jpn & 0,0 & $-7,6$ & 0,0 & $-6,6$ \\
asi & 0,0 & 15,1 & 0,0 & 12,2 \\
chn & 0,0 & 0,0 & 0,0 & 0,0 \\
rus & 0,0 & 0,0 & 0,0 & 0,0 \\
unk & 0,0 & $-3,1$ & 0,0 & $-2,1$ \\
ue27 & 0,0 & 0,0 & 0,0 & 0,0 \\
tpp & $-0,1$ & $-7,6$ & $-0,1$ & $-8,5$ \\
rm & 0,0 & 0,0 & 0,0 & 0,0 \\
\hline & & & & \\
\hline
\end{tabular}

Fonte: Resultados da pesquisa

No cenário 3, as simulações levaram em consideração o TPP com a redução de $40 \%$ das barreiras tarifárias, contando com a saída dos Estados Unidos do TPP. É possível verificar que, nesse cenário apenas de redução de barreiras, a saída dos Estados Unidos do acordo não acarreta em mudanças em termos de produção se comparados com o cenário 1 , que contava com o país como um membro do TPP.

Porém, no cenário 4, que além de pressupor a saída dos Estados Unidos, supõe a eliminação total das barreiras tarifárias e não tarifárias, gerando mudanças nos volumes de produção na maioria das regiões, se comparado com o cenário 2. Os Estados Unidos, apesar de apresentar ganhos em termos de produção, seus ganhos não participando do TPP são menores do que sendo membro do acordo, uma diferença de aproximadamente 85.000 toneladas. O mesmo ocorre com os demais países do NAFTA, o Peru, países da África, demais países da Ásia.

De maneira geral, verifica-se que os impactos do TPP sem a participação dos Estados Unidos são menos agressivos do que com a participação deste, tanto em ganhos e perdas de produção. Exceto para a Argentina, a Austrália, os demais países do Asean, e os demais países do TPP, que apresentam perdas superiores no caso da saída dos Estados Unidos. Principalmente pelo fato dos Estados Unidos intensificar suas relações de comércio com seus principais parceiros econômicos no cenário base, tendo em vista que ele não apresenta mais liberação comercial com os países do TPP. Esses parceiros econômicos do país, a partir da formação do TPP estavam sendo atendidos, em sua maioria, pelos países do MERCOSUL. Além disso, alguns países do TPP, como a Austrália, e os demais países do TPP, fortalecem relações comerciais com os demais membros, passando a importar mais do produto, devido às vantagens, passando a produzir em menor quantidade.

Ainda, verifica-se que a redução em termos de alavancagem da produção dos Estados Unidos, só não é maior, pelo motivo do país ser integrante do NAFTA, o qual atua como uma ponte até o TPP. Diante disso, os Estados Unidos enquanto membro do acordo, apresentava relações comerciais com os mais países do TPP, fora do acordo, exporta seu produto para os demais países do NAFTA, e este, reexporta aos membros do TPP.

\subsubsection{Análise dos Excedentes do Produtor e Consumidor}

Com a simulação do primeiro cenário, que supõe a formação do TPP, com a redução das barreiras tarifárias e a manutenção das questões não tarifárias, verificam-se singelas mudanças em termos de excedente de produtor nas regiões analisadas (Ver Tabela 4). Porém, as alterações mais significativas foram na Austrália (1,4\%) e nos países do Asean (0,3\%), o que significa ganhos de aproximadamente US\$44 milhões e US\$21 milhões, 
respectivamente. Os países do MERCOSUL, de maneira geral, apresentam perdas em relação a seus excedentes. No caso do Brasil $(0,2 \%)$, essa redução representa uma perda de US\$27 milhões aos seus produtores, no caso da Argentina $(0,1 \%)$ e no restante do MERCOSUL $(0,2 \%)$ essa redução representa US\$4 milhões e US\$260 mil, respectivamente. Além desses, observa-se reduções de excedentes do produtor no Japão, Arábia Saudita, Oriente Médio, Reino Unido, e nos demais países do TPP, tendo em vista as alterações nos fluxos comerciais e a redução dos preços.

TABELA 4 - Variações dos excedentes do produtor nos cenários alternativos em relação ao cenário base (\%)

\begin{tabular}{ccccc}
\hline Região & Cenário 1 & Cenário 2 & Cenário 3 & Cenário 4 \\
\hline bra & $-0,2$ & $-14,3$ & $-0,2$ & $-9,7$ \\
arg & $-0,1$ & $-12,8$ & $-0,1$ & $-13,1$ \\
mes & $-0,2$ & $-17,9$ & $-0,2$ & $-16,1$ \\
per & 0,0 & 35,5 & 0,0 & 27,5 \\
das & 0,0 & 1,1 & 0,0 & 0,0 \\
usa & 0,0 & 5,6 & 0,0 & 4,5 \\
naf & 0,0 & 24,5 & 0,0 & 19,5 \\
aus & 1,4 & $-4,3$ & 1,4 & $-6,2$ \\
mas & 0,0 & $-23,4$ & 0,0 & $-3,2$ \\
ase & 0,3 & $-9,8$ & 0,3 & $-14,1$ \\
afr & 0,0 & 42,3 & 0,0 & 33,2 \\
ome & $-0,1$ & $-10,5$ & $-0,1$ & $-7,0$ \\
sal & $-0,1$ & $-10,4$ & $-0,1$ & $-7,0$ \\
jpn & $-0,1$ & $-13,9$ & $-0,1$ & $-12,2$ \\
asi & 0,0 & 33,5 & 0,0 & 26,4 \\
chn & 0,0 & 0,0 & 0,0 & 0,0 \\
rus & 0,0 & 0,0 & 0,0 & 0,0 \\
unk & $-0,1$ & $-6,0$ & $-0,1$ & $-4,0$ \\
ue27 & 0,0 & 0,0 & 0,0 & 0,0 \\
tpp & $-0,1$ & $-14,2$ & $-0,1$ & $-15,7$ \\
rm & 0,0 & 0,0 & 0,0 & 0,0 \\
\hline
\end{tabular}

Fonte: Resultados da pesquisa

No segundo cenário, a partir da eliminação total das barreiras tarifárias e não tarifárias, as perdas aos países do MERCOSUL são acentuadas. Ao Brasil as perdas são próximas de $14 \%$, ou seja, aproximadamente US $\$ 2,2$ bilhões. O mesmo ocorre para a Argentina $(12,8 \%)$ e aos demais países do MERCOSUL (18\%), que representa perdas próximas a US\$380 milhões e US\$24 milhões, respectivamente. Tais reduções também foram verificadas em países como os demais países do TPP (14,2\%), Reino Unido (6\%), Japão (14\%), Arábia Saudita (10,4\%), Oriente Médio (10,5\%), demais países do Asean (9,8\%), Malásia $(23,4 \%)$ e Austrália (4,3\%). Porém, países como a Austrália, Malásia, Japão e demais países do TPP, são membros do acordo, e apresentam conjuntamente uma redução de US $\$ 1,8$ bilhões aos produtores de carne de frango.

Por outro lado, algumas regiões apresentam crescimento em termos de excedente do produtor, caso do Peru (35,5\%), demais países da América do Sul $(1,1 \%)$, Estados Unidos (5,6\%), demais países do $\operatorname{NAFTA}(24,5 \%)$, demais países da África (42,3\%) e demais países da Ásia $(33,5 \%)$. No caso dos países do NAFTA, esse incremento representa cerca de US\$6,7 bilhões aos produtores. Observa-se que as alterações nos excedentes do produtor devem-se a criação de desvio de comércio, motivado pela eliminação das barreiras tarifarias e não tarifarias entre os países membros do TPP. Beneficiando, em grande medida, os países mais produtivos e com preços mais competitivos dentro do bloco, como por exemplo, os Estados Unidos, os demais países do NAFTA e o Peru. Os quais assumem a demanda de membros como os demais países do TPP e do Japão. Tal demanda, anteriormente era atendida pelos países do MERCOSUL. Além disso, acaba forçando a produção de regiões como a África e a Ásia, para atender sua demanda interna, regiões que eram atendidas pelas exportações dos Estados Unidos.

A partir da simulação do cenário 3, que pressupõe a redução tarifária no TPP, além da saída dos Estados Unidos do acordo, verificou-se que as alterações obtidas mantiveram-se constantes às verificadas no cenário 1 , que contava com a participação dos Estados Unidos no TPP. Porém, no cenário 4, com a eliminação total das barreiras tarifárias e não tarifárias e a saída dos Estados Unidos do acordo, tais alterações afetam as regiões de forma menos significativa. Exceto para os demais países do TPP, demais países do Asean, Austrália e Argentina, que passam ou a importar mais, devido à facilitação do comércio, ou perdem parceiros econômicos aos membros do acordo pelo mesmo motivo.

Apesar do cenário 4 ser menos agressivo com o Brasil, o país apresenta perda de excedente de produtor próximo a $9,7 \%$, representa uma redução no seu quantitativo de US\$1,5 bilhões. Já a redução de excedente do produtor a Argentina e aos demais países do MERCOSUL, são próximos a US\$390 milhões e US\$21 milhões, respectivamente. Essa atenuação das perdas 
dos países do MERCOSUL, se deve ao fato dos Estados Unidos não possuir mais a preferência comercial que tirava dos países do MERCOSUL o mercado de alguns países do TPP, caso do Japão e dos demais países do TPP. Reduzindo os ganhos em termos de excedente de produtor aos Estados Unidos e aos demais países do NAFTA, onde seus ganhos passam a US $\$ 4,4$ bilhões e US\$1,0 bilhão, respectivamente.

Para complementar a análise do bem-estar, são apresentados os excedentes do consumidor (Ver Tabela 5). No primeiro cenário, observam-se ganhos aos consumidores do MERCOSUL. Tais ganhos são mais elevados com aprofundamento do TPP (cenário 2), passando de 0,1\% para 10\% no caso do Brasil. Quando simulado o TPP com redução das barreiras tarifárias e a saída dos Estados Unidos, caso do cenário 3, os excedentes do consumidor apresentam variações marginais, porém, não se diferem das estimações do cenário 1, que contava com os Estados Unidos membro do TPP.

TABELA 5 - Variações dos excedentes do consumidor nos cenários alternativos em relação ao cenário base (\%)

\begin{tabular}{ccccc}
\hline Região & Cenário 1 & Cenário 2 & Cenário 3 & Cenário 4 \\
\hline bra & 0,1 & 10,0 & 0,1 & 6,5 \\
arg & 0,1 & 5,9 & 0,1 & 6,0 \\
mcs & 0,1 & 5,3 & 0,1 & 4,7 \\
per & 0,0 & $-23,7$ & 0,0 & $-19,1$ \\
das & 0,0 & $-0,9$ & 0,0 & 0,0 \\
usa & 0,0 & $-7,3$ & 0,0 & $-5,9$ \\
naf & 0,0 & $-15,1$ & 0,0 & $-12,3$ \\
aus & $-1,1$ & 3,4 & $-1,1$ & 5,1 \\
mas & 0,0 & 22,7 & 0,0 & 2,6 \\
ase & $-0,3$ & 11,7 & $-0,3$ & 17,4 \\
afr & 0,0 & $-31,2$ & 0,0 & $-25,8$ \\
ome & 0,1 & 7,3 & 0,1 & 4,8 \\
sau & 0,1 & 11,4 & 0,1 & 7,5 \\
jpn & 0,1 & 15,0 & 0,1 & 12,1 \\
asi & 0,0 & $-23,5$ & 0,0 & $-19,2$ \\
chn & 0,0 & 0,0 & 0,0 & 0,0 \\
rus & 0,0 & 0,0 & 0,0 & 0,0 \\
unk & 0,1 & 5,7 & 0,1 & 3,7 \\
ue27 & 0,0 & 0,0 & 0,0 & 0,0 \\
tpp & 0,1 & 12,6 & 0,1 & 14,1 \\
rm & 0,0 & 0,0 & 0,0 & 0,0 \\
\hline
\end{tabular}

Fonte: Resultados da pesquisa
Porém, em um cenário mais agressivo do TPP, sem os Estados Unidos, os ganhos em termos de excedentes do consumidor são inferiores aos estimados no cenário 2. O Brasil passa a apresentar uma variação de $6,5 \%$, em termos quantitativos, essa variação representa cerca de US\$1,3 bilhão. Esse ganho em termos de excedente do consumidor se deve ao redirecionamento dos fluxos comerciais, ocasionando a redução dos preços do Brasil, estimulando o consumo interno.

Alguns países apresentam perdas significativas em relação aos excedentes do consumidor. Caso do Peru, Estados Unidos, demais países do NAFTA, países da África, e demais países da Ásia, especialmente nos cenários 2 e 4. Nos cenários 1 e 3, não se verificou alterações nos excedentes a essas regiões. Fato que corrobora para isso, é que não houve alterações nas condições de comércio, pois os cenários simulam apenas alterações de barreiras tarifárias e manutenção das barreiras não tarifárias.

Regiões como a China, Rússia, União Europeia e resto do mundo, não apresentaram mudanças em suas relações de comércio em nenhum dos cenários simulados. Provavelmente, pelo fato que esses países conseguem atender sua demanda interna com sua produção, apresentando pouca dependência do mercado externo. Porém, em seu estudo, Aslan et al (2015) estimaram perdas significativas para a China, na ocorrência do TPP, em análise do PIB, das importações e das exportações, o que não foi verificado nesse estudo no setor de carne de frango.

Em análise dos impactos das alterações nos excedentes ao Brasil, observa-se que ocorrem ganhos em termos de excedente de produtor inferiores as perdas dos produtores, ou seja, há uma perda líquida de bem-estar ao Brasil, considerando a formação do TPP. Resultado semelhante foi observado por Medeiros e Bender Filho (2019) em análise da carne de frango; Silva (2018) no setor industrial; e Silva (2017) para o agronegócio, enfatizando que o setor de carnes é um dos mais prejudicados com a formação do TPP, situação agravada com a estimação de um cenário mais abrangente, ou seja, com maior liberalização. Nesse sentido, Thorstensen e Ferraz (2014), afirmam que o TPP deve apresentar impactos negativos à economia brasileira, podendo ser mais significativos com os ganhos de competitividade dos países membros do acordo. Em análise alternativa, Cunha (2018) mensurou os impactos de uma possível participação do Brasil no acordo, os resultados indicam vantagens comparativas ao setor do agronegócio, impactando positivamente a cadeia de carne de suíno e aves, entre outros. 
De maneira geral, verifica-se que os países do NAFTA, apresentam ganhos de excedentes do produtor com a formação do TPP, porém, em menor proporção dada a não participação dos Estados Unidos no acordo. Com a formação do TPP, os Estados Unidos e os demais países do NAFTA, apresentam um redirecionamento das suas exportações aos países do acordo. O mesmo foi verificado por Petri e Plummer (2016); López, García e España (2018) e Jimenez, Gomez e Paniagua (2018), o TPP beneficiará substancialmente os membros, não havendo significativas alterações nos fluxos comerciais dos EUA. Tendo em vista que o país capta parte das exportações agrícolas dentro do TPP, concluído por Burfisher (2014).

\section{CONCLUSÕES}

A partir da formação do TPP, e posteriormente a saída dos Estados Unidos do acordo, esse estudo buscou analisar as alterações no comércio internacional de carne de frango, dada a retirada dos Estados Unidos do TPP, utilizando do Equilíbrio Espacial e do Problema de Complementaridade Mista (PCM), a partir de simulações de quatro cenários alternativos, que representavam as propostas de redução conforme o acordo.

O primeiro cenário figura a formação do TPP com a redução de $40 \%$ das barreiras tarifárias, enquanto que o cenário 2 , supôs a eliminação total das barreiras tarifarias e também não tarifárias aos países-membros. Contando com a saída dos Estados Unidos do TPP, os cenários 3 e 4 consideravam a redução de $40 \%$ das tarifas, e a eliminação das barreiras tarifarias e não tarifárias, respectivamente.

A partir das estimações, verificou-se que a formação do TPP, de maneira geral, traz prejuízos ao setor brasileiro de carne de frango, em termos de produção, preços e excedentes do produtor. Sendo que o cenário mais prejudicial ao país consiste na formação original do TPP, a partir da eliminação total das barreiras. Porém, essa perda é atenuada no caso da saída dos Estados Unidos do acordo. Apesar de verificarem-se ganhos nos excedentes do consumidor, esses ganhos não são suficientes para anular as perdas verificadas nos excedentes do produtor, assim, o país apresenta uma perda líquida de bem-estar.

Ao Brasil, reforça-se a importância de negociações comerciais, para que seja possível que o país acompanhe as mudanças no cenário mundial. Além disso, algumas medidas internas também são indispensáveis, como a ampliação da capacidade produtiva, rigor na saúde animal, e na fiscalização e certificação do produto, pois, essas questões são impactantes no comércio internacional.
Ademais, a formação do TPP apresenta ganhos aos países como o Peru, Estados Unidos e os demais países do NAFTA. Porém, esses ganhos são reduzidos no caso da saída dos Estados Unidos do acordo. Apesar dos Estados Unidos alcançarem os países do TPP com o NAFTA atuando com uma ponte a esses países. Evidencia-se a importância da participação dos Estados Unidos no TPP, ou seja, a adoção de políticas protecionistas atenua os ganhos comerciais do país, no setor de carne de frango.

Apesar dos resultados retratarem as condições reais de comércio, destacam-se algumas limitações do estudo, essencialmente pelo fato das elasticidades referirem-se a carnes, no ano de 1996. Assim, foram necessários ajustes para atender os critérios de calibragem. Além disso, ressaltase a inexistência de informações relacionadas ao custo de transporte marítimo do produto, para isso, foi necessário o uso de estimativas, levando como base as tarifas portuárias disponibilizadas pelo Porto de Rio Grande. Para futuros estudos, sugere-se alterações em termos de subsídios aos produtores, tendo em vista o potencial que essas alterações possuem diante dos fluxos comerciais, além disso, recomenda-se a simulação da participação de países não membros no acordo, como por exemplo a China e o Brasil.

\section{REFERÊNCIAS}

ALVIM, A. M.; WAQUIL, P. D. Os Efeitos do Livre Comércio sobre o Mercado de Grãos no Brasil. Análise Econômica, Porto Alegre: UFRGS, v. 25, n. 47, 2007.

AMARAL, G. G.; MATTOS, T. C. L. A PARCERIA TRANS-PACÍFICO COMO UMA ESTRATÉGIA DE CONTENÇÃO DA CHINA. Revista Aurora, Marília, v. 7, n. 1, jul./dez., 2013.Disponível em: <http://www2. marilia.unesp.br/revistas/index.php/aurora/article/ view/3399/2721>. Acessoem: 06 mar. 2017.

ARMSTRONG, S. P. Australia and the future of the TransPacific Partnership Agreement. 2011. EABER. Beijing, Paper No. 71, December, 2011. Disponível em: <http:// papers.ssrn.com/sol3/papers.cfm?abstract_id=1970129>. Acessoem: 13 mar. 2017.

ASLAN, B.; KUTUK, M. M.; ODUNCU, A. Transatlantic Trade and Investment Partnership and Trans-Pacific Partnership: Policy Options of China. China \& World Economy, v. 23, n. 6, nov./dez, p. 22-43, 2015. Disponível em: <http://onlinelibrary.wiley.com/doi/10.1111/ cwe.12134/full>. Acesso em: 6 mar. 2017. 
BANCO MUNDIAL. World DevelopmentIndicators, 2005. Disponível em: <http://www.worldbank.org>. Acesso em: 1 mai. 2016.

BENDER FILHO, R. O mercado de carne bovina no Brasil: os efeitos da eliminação das barreiras tarifárias e não tarifárias. 2006. 136 p. Dissertação (Mestrado em Economia)-Pontifícia Universidade Católica do Rio Grande do Sul, Porto Alegre, 2006.

BENDER FILHO, R.; ALVIM, A. M. O mercado de carne bovina no Brasil: os efeitos da eliminação das barreiras tarifárias e não-tarifárias. Revista de Economia e Sociologia Rural, v. 46, n. 4, p. 1095-1127, 2008.

BURFISHER, M. E. et al. Agriculture in the TransPacific Partnership. USDA-ERS Economic Research. Washington, 2014. Disponível em: < http://www.ers. usda.gov/media/1692500/err176_summary.pdf $>$. Acesso em 27 jan. 2017.

CALDAS, C. Trump assina retirada dos EUA da Parceria Transpacífico. Zero Hora, Porto Alegre, 23 jan. 2017. Disponível em: <http://zh.clicrbs.com.br/rs/noticias/ mundo/noticia/2017/01/trump-assina-retirada-dos-euada-parceria-transpacifico-9537727.html> . Acesso em: 20 fev. 2017.

CARNEIRO, F. L. A Parceria Transpacífica: Principais características e impactos sobre a regulação do comércio mundial. Boletim de Economia e Política Internacional, n. 18, Set./Dez. 2014.

CUNHA, C. P. da. Os impactos do TPP e RCEP sobre o agronegócio brasileiro: análise por meio de um modelo de equilíbrio geral computável. Dissertação (Mestrado em Agronegócio) - Escola de Economia de São Paulo, Fundação Getulio Vargas, 2018.

FERGUSSON, I. F; MCMINIMY, M. A; WILLIAMS, B. R. The Trans-Pacific Partnership (Tpp) Negotiations and Issues for Congress. 2011. Congressional Research Service. Washington, 2015. Disponível em: $<$ https://www. fas.org/sgp/crs/row/R42694.pdf>. Acessoem: 13 jan. 2016.

FERGUSSON, I. F. VAUGHN, B. The Trans-Pacific Partnership Agreement. Congressional Research Service. Washington. 2011. Disponívelem: <https:/www.fas.org/ sgp/crs/row/R40502.pdf $>$. Acessoem: 13 jan. 2016.
FOOD AND AGRICULTURAL ORGANIZATION OF THE UNITED NATIONS - FAO. FAO Statistics Series. Roma, 2016. Disponível em: <http://faostat3.fao.org/ home/>. Acesso em: 2 fev. 2016.

GRÜNDLING, R. D. P.; WAQUIL, P. D. Efeitos de acordos comerciais sobre o setor de carne bovina no Mercosul. Revista de Economia e Agronegócio-REA, v. 5, n. 4, 2015.

JIMENEZ, Z. T. I.; GOMEZ, P. O.; PANIAGUA, C. O.. La inserción de México al TPP como estrategia para potencializar el comercio y lasinversiones. México y la cuenca del pacífico, v. 7, n. 21, p. 121-143, 2018.

LÓPEZ, L. R.; GARCÍA, E. A. H.; ESPAÑA, V. A. D. The Pacific Alliance and the potential effects of a Trans-Pacific Economic Cooperation Agreement without the United States. Revista Finanzas y Política Económica, v. 10, n. 1, p. 65-110, 2018.

MINISTÉRIO DO DESENVOLVIMENTO, INDÚSTRIA E COMÉRCIO EXTERIOR -MDIC. Simulador de preço de exportação. Brasília, 2016. Disponível em: $<$ http:// simuladordepreco.mdic.gov.br/>. Acesso em: 1 mai. 2016.

MEDEIROS, A. P. de; BENDER FILHO, R. Mercado de carne de frango brasileiro no contexto dos novos acordos regionais de comércio: Transpacífico e Transatlântico. Rev. Econ. Sociol. Rural, v. 57, n. 4, p. 618-635, 2019.

MERCURIO, B. The Trans-Pacific Partnership: Suddenly a 'Game Changer'. The World Economy, v. 37, n. 11, p. 1558-1574. 2014.

MIYAZAKI, S. Y. M. A economia política da política comercial Japonesa: das propostas de integração econômica ao Tratado de Parceria do Pacífico (TPP). Tese (Livre Docência) - Escola de Artes, Ciências e Humanidades, Universidade de São Paulo, 2019.

NAGURNEY, A., NICHOLSON, C. F., BISHOP, P. M. Spatial price equilibrium models

with discriminatory ad valorem tariffs: formulation and comparative computation using variational inequalities. In:

VAN DEN BERGH, J.C.J.M., NIJKAMP, P., RIETVELD, P. (eds). Recent Advances in Spatial Equilibrium Modelling: methodology and applications. New York: Springer, 1996. 
NAKAGAWA, J. TPP-11 as a Means to Revive the TPP after US'Withdrawal. Asian Journal of WTO \& International Health Law\& Policy, v. 12, p. 405, 2017.

NUNESLINS, H.Parceria Trans-Pacífico: Novas Geometrias no Capitalismo Global. ContextoInternacional, v. 36, n. 2, p. 623-653. 2014.

OFFICE OF THE UNITED STATES TRADE REPRESENTATIVE. Outlines of the Trans-Pacific Partnership Agreement. Washington, 2011. Disponível em: <https://ustr.gov/about-us/policy-offices/pressoffice/fact-sheets/2011/november/outlines-trans-pacificpartnership-agreement> Acesso em: 14 mar. 2017.

Trans-Pacific Partnership Ministers' Statement. Washington, 2016. Disponível em: <https:// ustr.gov/about-us/policy-offices/press-office/pressreleases/2016/February/TPP-Ministers-Statement $>$. Acesso em: 10 mar. 2017.

ORGANIZAÇÃO MUNDIAL DO COMÉRCIO - OMC. Portal Integrado de Informação Comercial. Genebra, 2016. Disponível em: <http://i-tip.wto.org/goods/Default. aspx>. Acessoem: 01 mai. 2016.

ORGANIZATION FOR ECONOMIC CO-OPERATION AND DEVELOPMENT - OECD. Agricultural policies in OECD countries: monitoring and evaluation 2005. Paris, 2005. Disponível em: <http://www.oecd.org/tad/ agricultural-policies/35016763.pdf $>$. Acesso em: 01 mai. 2016.

PETRI, P. A; PLUMMER, M. G. The Economic Effects of the Trans-Pacific Partnership: New Estimates. Peterson Institute for International Economics Working Paper, n. 16-2, 2016. Disponívelem: <https://piie.com/system/ files/documents/wp16-2_0.pdf>. Acessoem: 26 out. 2016.

PORTO DE RIO GRANDE. Tarifa portuária. Rio Grande, 2016. Disponível em: <http:/www.portoriogrande.com.br/ site/estrutura_portuaria_tarifas.php $>$. Acessoem: 01 mai. 2016.

RODRIGUEZ, G.; DÁVALOS, J. The Trans-Pacific Partnership Agreement (TPP) Trade Potential for Peru, a Gravity Model Approach. GECONTEC: Revista Internacional de Gestión del Conocimiento y laTecnología, v. 5, n. 2, p. 93-107, 2017.
SAMUELSON, P. A. Spatial price equilibrium and linear programming. The American economic review, v. 42, n. 3, p. 283-303, 1952. Disponível em: <ttp://www.jstor. org/stable/pdf/1810381.pdf?acceptTC $=$ true $>$. Acesso em: 6 jan. 2016.

SILVA, R. A. Impactos do acordo de preferência comercial transpacífico no agronegócio brasileiro. Dissertação (Mestrado em Administração) - Universidade Federal de Santa Maria, 2017.

SILVA, M. L. da. O setor industrial brasileiro frente à integração econômica. Tese (Doutorado em Administração) - Universidade Federal de Santa Maria, 2018.

TAKAYAMA, T; JUDGE G. G. Equilibrium among spatially separated markets: a reformulation. Econometrica, p. 519-524, 1964. Disponível em: <http://www.jstor. org/stable/1910175?seq=1\#page_scan_tab_contents $>$. Acessoem: 23 jan. 2016.

THORSTENSEN, V; FERRAZ, L.The impacts of TTIP and TPP on Brazil.Fundação Getúlio Vargas, 2014. Disponível em: <http://ccgi.fgv.br/sites/ccgi.fgv.br/files/ file/Publicacoes/TTIP\%20e\%20TPP\%20(ENG)\%20 16.01,14.pdf $>$ Acesso em: 18 jan. 2017.

UNITED STATES DEPARTMENT OF AGRICULTURE. FOREIGN AGRICULTURAL SERVICE - USDA. World supply and distribution online. Washington, 2016 a. Disponível em: <http://www.fas.usda.gov/psdonline> Acesso em: 20 jan. 2016.

Commodity and Food Elasticities. Washington, 2016b. Disponível em: <http://www.ers.usda.gov/dataproducts/commodity-and-food-elasticities.aspx $>$ Acesso em: 20 mai. 2016.

UNITED STATES TRADE REPRESENTATIVE - USTR. 18,000 Tax Cuts on Made-in-America Exports: A guide to How Tax Cuts Will Benefit Exporting in Your State. Washington, 2014. Disponível em: <https://ustr.gov/sites/ default/files/TPP-Guide-to-18000-Tax-Cuts.pdf $>$. Acesso em: 20 jan. 2017.

TariffElimination Schedule. Washington, 2015. Disponível em: <https://ustr.gov/trade-agreements/freetrade-agreements/trans-pacific-partnership/tpp-full-text $>$. Acesso em: 2 fev. 2017. 